\title{
Perspectivas de Futuro Profissional para Jovens Provenientes de Classes Socioeconômicas Desfavorecidas
}

\author{
Gênesis Marimar Rodrigues Sobrosa ${ }^{\mathbf{1}}$ \\ Programa de Pós-Graduação em Psicologia pela Universidade do Vale do Rio dos Sinos, \\ São Leopoldo, Rio Grande do Sul, Brasil \\ Anelise Schaurich dos Santos \\ Clarissa Tochetto de Oliveira \\ Programa de Pós-Graduação em Psicologia, Universidade Federal de Santa Maria, \\ Santa Maria, Rio Grande do Sul, Brasil \\ Ana Cristina Garcia Dias \\ Departamento do Curso de Psicologia e Programa de Pós-Graduação em Psicologia, \\ Universidade Federal de Santa Maria, Santa Maria, Rio Grande do Sul, Brasil
}

\section{Resumo}

O objetivo desse estudo foi investigar as expectativas em relação ao futuro profissional de jovens estudantes do ensino médio oriundos de classes socioeconômicas desfavorecidas. Participaram desse estudo 200 estudantes de ensino médio de ambos os sexos que frequentavam duas escolas públicas estaduais no interior do Rio Grande do Sul. A coleta de dados foi realizada coletivamente, em sala de aula, através de um questionário que continha questões abertas e fechadas. Os dados das questões abertas foram submetidos à análise de conteúdo temática e das questões fechadas, a análises estatísticas. Constatou-se que a maioria dos estudantes pensa a respeito de seu futuro profissional. Esses pensamentos estão relacionados tanto ao esforço pessoal para conquistar sucesso profissional e pessoal e boas condições financeiras, quanto ao desejo que os jovens possuem de exercer uma profissão que lhes traga satisfação pessoal. De maneira geral, os jovens são otimistas em relação ao futuro profissional e esperam conquistar sucesso nos diversos contextos de vida. No entanto, os participantes reconhecem a necessidade de se esforçar para atingir seus objetivos e desfrutar da satisfação que o trabalho pode proporcionar, uma vez que percebem os aspectos negativos associados à instabilidade do mercado de trabalho.

Palavras-chave: Jovens, ensino médio, profissão, futuro.

\section{Perspectives of Young People from Lower Classes Regarding the Professional Life}

\begin{abstract}
The aim of this study was to investigate the expectations of high school students from lower classes regarding their future as a professional. The sample was composed of 200 high school students, male and

1 Endereço para correspondência: Rua José Mário Mônaco, 13, Apto. 805, Centro, Bento Gonçalves, RS, Brasil 95700-000. E-mail: genesispsi@yahoo.com.br, anelise_ssantos@hotmail.com, clarissa.tochetto@gmail.com e anacristinagarciadias@gmail.com

Agência de Financiamento: Programa de Apoio ao Plano de Reestruturação e Expansão das Universidades (REUNI).

Este artigo deriva da Dissertação de Mestrado da primeira autora, realizada no Programa de Pós-Graduação em Psicologia da Universidade Federal de Santa Maria, sob orientação da quarta autora. A pesquisa contou com o apoio financeiro do Programa de Apoio ao Plano de Reestruturação e Expansão das Universidades - REUNI.
\end{abstract}


female, from two public schools of Rio Grande do Sul. Data were gathered all together in classrooms through a questionnaire composed by open and closed questions. The data from open questions were submitted to content analysis and the data from closed questions were submitted statistical analysis. Results demonstrated that the majority of the students think about the future of their professional life. Their thoughts are related not only to the effort they must make to achieve professional and personal success and to improve their financial conditions, but also to their desire to work in something that gives them satisfaction. In general, the participants showed to be optimistic about their future as a professional and hopeful to achieve success in their personal and professional life. On the other hand, the students recognized they need to struggle to achieve their goals and enjoy the satisfaction work can provide, once they noticed the negative aspects associated to the instability of the labor market.

Keywords: Young adults, secondary education, profession, future.

\section{Perspectivas del Futuro Profesional para Jóvenes Provenientes de Clases Socioeconómicas Desfavorecidas}

\section{Resumen}

El objetivo de este estudio fue investigar las expectativas respecto al futuro profesional de jóvenes de Secundaria oriundos de clases socioeconómicas desfavorecidas. Participaron del estudio 200 estudiantes de Secundaria de ambos sexos que acudían a dos escuelas públicas estaduales en el interior de Río Grande del Sur. La colección de datos se realizó colectivamente, en el aula, por medio de un cuestionario que contenía preguntas abiertas y cerradas. Los datos de las cuestiones abiertas fueron sometidos a análisis de contenido temático, y los de las cerradas, a análisis estadístico. Se halló que la mayoría de los estudiantes piensa respecto a su futuro profesional. Esos pensamientos se relacionan tanto con el esfuerzo personal, para lograr el éxito personal, profesional y buenas condiciones financieras; como al deseo que los jóvenes poseen de ejercer una profesión que les traiga satisfacción personal. De manera general, los jóvenes son optimistas respecto al futuro profesional y esperan lograr el éxito en los diversos contextos de la vida. Sin embargo, los participantes reconocen la necesidad de esforzarse para llegar a sus objetivos y desfrutar de la satisfacción que el trabajo puede proporcionar, ya que perciben los aspectos negativos asociados a la instabilidad del mercado laboral.

Palabras-clave: Jóvenes, secundaria, profesión, futuro.

Verifica-se que muitos trabalhadores não são absorvidos no mercado de trabalho em função de uma qualificação profissional deficiente, o que pode resultar em elevadas taxas de desocupação, especialmente para os mais jovens (Rocha, 2008). A exigência de maior qualificação, bem como a necessidade de pessoas especializadas para trabalhar com novas tecnologias e novas formas de gestão do trabalho, contribuíram para o surgimento de inúmeros cursos de aperfeiçoamento no Brasil. Nesse sentido, a preparação para o mercado de trabalho se torna permanente (Melo \& Borges, 2007). Além disso, hoje, no mundo do trabalho, se exige que as pessoas sejam flexíveis, criativas, pró-ativas, busquem qualificação de maneira contínua e estejam preparadas para mudanças de cargos, funções ou mesmo empregos (Burnier, 2006; Lemos, Dubeux, \& Pinto, 2009; Nunes \& Noronha, 2009). Assim, a necessidade da busca constante por empregos e qualificação educacional, que possibilitam a sustentação no mercado de trabalho, faz com que tanto a entrada na universidade quanto no ambiente organizacional seja realizada em um contexto de ansiedade (Bardagi, Lassance, \& Paradiso, 2003).

A mudança do ensino médio para a universidade, ou para o mundo do trabalho, pode ser permeada por dificuldades para a maioria dos jovens. Inúmeras vezes adicionam-se a essa tran- 
sição obstáculos culturais e econômicos, principalmente, quando se trata de jovens provenientes de classes econômicas desfavorecidas. Nesses cenários, a escolha da profissão, do curso universitário ou técnico, sobretudo em condições adversas, caracteriza-se pela busca de equilíbrio entre o objetivo almejado e o que é possível de ser realizado (Gonçalves et al., 2008). Segundo Gottfredson (1981), os obstáculos ou as oportunidades que são determinadas a partir do contexto social e/ou econômico ao qual o jovem pertence podem comprometer as chances de alguém ingressar em uma determinada ocupação. Frequentemente, o indivíduo faz uma avaliação a respeito de sua possibilidade de acessar determinada profissão. Este juízo acaba por interferir seriamente no sentido de tal alternativa ser considerada como viável ou não. Nesse sentido, o autor considera que tais julgamentos levam em conta diversos fatores como: a disponibilidade do trabalho pretendido dentro da área geográfica do indivíduo, a facilidade ou não para obter um treinamento para o trabalho pretendido, o conhecimento ou a falta do mesmo para ingressar em determinada ocupação.

A inserção em um curso universitário, por exemplo, é uma tarefa que requer dedicação e persistência dos jovens, especialmente daqueles de classes econômicas desfavorecidas. Eles possuem maiores chances de não receber uma educação de qualidade que os permita concorrer por vagas no ensino superior em iguais condições aos estudantes oriundos de camadas econômicas mais privilegiadas (Brito, 2006; Sobrosa, Camerin, Santos, \& Dias, 2012). Apesar dos jovens provenientes de classes socioeconômicas desfavorecidas perceberem a escola como um lugar de aprendizagem e crescimento (Brito, 2006), os mesmos podem encontrar dificuldades para ter acesso a cursos de qualificação profissional (Sobrosa et al., 2012). Ademais, a desocupação em termos de posto de trabalho é maior entre os jovens desfavorecidos economicamente (Ribeiro \& Neder, 2009). Mesmo assim, os estudantes acreditam que é possível garantir a sua sobrevivência e de seus familiares através de sua inserção no mercado de trabalho. Dessa forma, o trabalho e a escolarização destacam-se como possibilidades de ascender a posições mais dignas na sociedade (Brito, 2006), e de desvincularem-se financeira da família de origem, em uma busca de autonomia frente ao mundo adulto (Lachtim \& Soares, 2011).

No entanto, mesmo que os jovens de classes socioeconômicas desfavorecidas ingressem em um curso universitário ou técnico, normalmente eles não conseguem manter-se por muito tempo no sistema. Essa dificuldade é decorrente da tentativa de conciliar a jornada de trabalho com as atividades relativas aos estudos (Almeida, Guisante, Soares, \& Saavedra, 2006). Além disso, mesmo os indivíduos pertencentes a classes economicamente desfavorecidas e que obtiveram um maior nível de escolarização não alcançam taxas de emprego comparáveis com os jovens provenientes de classes de maior poder econômico. Dessa forma, é possível que os jovens com maiores taxas de desocupação enfrentem dificuldades no processo de transição para a vida adulta, a qual corresponderia, em tese, a uma etapa com maior autonomia e independência financeira (Ribeiro \& Neder, 2009). Diante dos obstáculos mencionados, considera-se relevante investigar as expectativas de estudantes do ensino médio provenientes de classes socioeconômicas desfavorecidas em relação ao futuro profissional. Nesse sentido, buscou-se conhecer o que os jovens pensam e sentem a respeito da sua inserção no mercado de trabalho e futuro profissional.

\section{Método}

\section{Participantes}

Participaram desse estudo 200 estudantes de ensino médio de ambos os sexos $(65 \%$ mulheres) que frequentavam o ensino médio $(48,5 \%$ do terceiro ano, $28 \%$ do segundo ano e $23,5 \%$ do primeiro ano) em duas escolas públicas estaduais da cidade de Santa Maria. Essas escolas estavam situadas em bairros de periferia, caracterizados por um nível socioeconômico desfavorecido. A idade dos participantes variou entre 14 e 26 anos ( $m=16,88 ; D P=1,62)$. A maior parte dos alunos frequentava o turno da manhã (49,5\%), sendo que $29 \%$ dos jovens estudava a noite e $21,5 \%$ freqüentava o turno da tarde. Observou-se que 
$50 \%$ dos estudantes que participaram da pesquisa apontaram que já reprovaram alguma vez na vida. Destes, $27,5 \%$ relataram ter reprovado uma vez, $16,5 \%$ duas vezes, $4 \%$ três vezes e $2 \%$ mais de quatro vezes.

\section{Instrumento e Procedimentos}

$\mathrm{O}$ instrumento continha questões abertas e fechadas que investigavam dados sócio demográficos, planos para o futuro dos jovens, motivos para a escolha de cursos técnicos ou universitários e dificuldades percebidas para o prosseguimento dos projetos educacionais e profissionais almejados. O projeto de pesquisa foi apresentado, com seus objetivos e procedimentos éticos e metodológicos à diretoria da escola, sendo solicitada a colaboração da mesma através da autorização para a realização do estudo na instituição. Esse procedimento foi repetido com os professores e estudantes, solicitando aos mesmos a colaboração para o desenvolvimento do estudo. O questionário anônimo foi respondido, coletivamente em sala de aula. O tempo previsto e utilizado na aplicação do instrumento foi de aproximadamente trinta minutos. A pesquisa foi desenvolvida observando os preceitos éticos da Resolução 196/96 do Conselho Nacional de Saúde (Ministério da Saúde, 1997) sendo aprovada pelo Comitê de Ética de Pesquisa da Universidade, com o número de protocolo 0249.0.243.000-10.

\section{Análise das Informações}

Foi utilizada uma análise de conteúdo temática para avaliar as questões abertas. Também foram realizadas estatísticas descritivas, quando necessárias para análise de questões fechadas. A análise de conteúdo é um conjunto de técnicas de análise das comunicações que utiliza procedimentos sistemáticos e objetivos, que permitem inferir conhecimentos a partir do conteúdo das mensagens analisadas (Bardin, 2009). Este tipo de análise busca a produção de inferências a respeito do conteúdo da comunicação, trabalhando com a palavra, a partir da categorização de unidades de texto repetidas. As respostas foram divididas em unidades segundo reagrupamentos analógicos (Minayo, 2000), procurando por nú- cleos de sentido e analisando a frequência dos mesmos (Bardin, 2009).

\section{Resultados}

Foi questionado se os estudantes pensam sobre o seu futuro profissional. A maioria dos alunos (94\%) respondeu que sim, 4,5\% responderam que não e $1,5 \%$ não responderam a essa pergunta. A Tabela 1 apresenta o que os 188 participantes pensam sobre seu futuro profissional. Destaca-se que dentre estes respondentes, $18,08 \%$ relacionaram o futuro profissional ao esforço pessoal, $17,55 \%$ ao sucesso profissional e pessoal, 9,04\% a boas condições financeiras, $7,45 \%$ ao gostar da profissão e $5,85 \%$, ofereceram outras respostas para falar de seu futuro profissional. O critério para a categorização das respostas fornecidas pelos participantes foi a semelhança entre os conteúdos apresentados. Alguns estudantes afirmaram pensar sobre o futuro profissional, porém não indicaram o que, de fato, pensam a respeito disso. Esses jovens são descritos na Tabela 1 como aqueles que "não responderam a questão".

A categoria que obteve maior percentual de respostas a essa questão foi esforço pessoal, os jovens indicaram a necessidade de buscar qualificação profissional para atingir seus objetivos. Exemplos de respostas congregados nessa categoria são: "eu penso que preciso estudar muito, pois o que eu quero não é fácil", "será bom desde que eu me esforce" e "vou ter que me qualificar, fazer cursos para aprender mais". A segunda categoria mais citada foi sucesso profissional e pessoal, essa categoria contou com afirmações como "quero ser uma boa profissional", "ser alguém na vida" e "que vou conseguir os meus sonhos". A categoria boas condições financeiras reuniu afirmações do tipo "quero poder com meu futuro profissional conseguir tudo o que eu desejo economicamente" e "ganhar muito dinheiro". Por sua vez, a categoria gostar da profissão abarca descrições como "que seja bom e que eu faça algo que goste" e "espero que o que eu escolher se identifique como eu sou". Por fim, a categoria dúvidas quanto à autoeficácia pode ser 
Tabela 1

O que os Alunos Pensam sobre Seu Futuro Profissional

\begin{tabular}{lcc}
\hline O que pensam sobre o futuro profissional & Frequência & Percentual \\
\hline Esforço pessoal & 34 & 18,08 \\
Sucesso profissional e pessoal & 33 & 17,55 \\
Boas condições financeiras & 17 & 9,04 \\
Gostar da profissão & 14 & 7,45 \\
Outras respostas & 11 & 5,85 \\
Dúvidas quanto à autoeficácia & 9 & 4,79 \\
Não sabem & 3 & 1,60 \\
Não responderam a questão & 67 & 35,64 \\
\hline Total & 188 & 100 \\
\hline
\end{tabular}

exemplificada pelas afirmações: "tenho medo de não saber exercer a profissão direito" e "se vou ser bem sucedida ou não".

Os alunos também indicaram como se sentem quando pensam no seu futuro profissional. A Tabela 2 apresenta as respostas fornecidas para essa questão. Para tanto, foi utilizada uma escala do tipo Likert sendo que o número 1 re- presenta a resposta muito pessimista, e o número 7 muito otimista. Os valores intermediários que foram marcados entre essas extremidades indicam respostas com uma maior ou menor proximidade desses extremos. Os estudantes relataram se sentir mais otimistas do que pessimistas. Quatorze participantes não responderam a essa questão.

\section{Tabela 2}

\section{Como os Alunos se Sentem quando Pensam no Seu Futuro Profissional}

\begin{tabular}{lccc}
\hline $\begin{array}{l}\text { Quando você pensa em seu futuro } \\
\text { profissional, você é? }\end{array}$ & Frequência & Percentual & $\begin{array}{r}\text { Percentual } \\
\text { acumulado }\end{array}$ \\
\hline 1 Muito pessimista & 8 & 4,0 & 4,0 \\
2 & 1 & 0,5 & 4,5 \\
3 & 5 & 2,5 & 7,0 \\
4 & 13 & 6,5 & 13,5 \\
5 & 28 & 14,0 & 27,5 \\
6 & 37 & 18,5 & 46,0 \\
7 Muito otimista & 94 & 47,0 & 93,0 \\
Não responderam a questão & 14 & 7,0 & 100,0 \\
\hline Total & 200 & 100 & 100 \\
\hline
\end{tabular}

Os jovens também foram questionados sobre o que pensam da situação atual do mercado de trabalho. A Tabela 3 apresenta as respostas dos participantes. Os estudantes consideram que o mercado de trabalho está difícil $(35,5 \%)$ e competitivo, por isso, é necessário qualificação dos profissionais (32\%). Uma parcela menor de participantes considerou a situação do mercado de trabalho boa $(14,5 \%)$. Vinte e seis participantes não responderam a questão. 
Tabela 3

O que os Alunos Pensam da Situação Atual do Mercado de Trabalho

\begin{tabular}{lcc}
\hline O que pensam da situação atual do mercado de trabalho? & Frequência & Percentual \\
\hline Difícil & 71 & 35,5 \\
Mercado competitivo/ que exige qualificação & 64 & 32,0 \\
Boa & 29 & 14,5 \\
Não sei & 4 & 2,0 \\
Desvalorização do profissional & 3 & 1,5 \\
Resposta insuficiente & 3 & 1,5 \\
Não responderam a questão & 26 & 13,0 \\
\hline Total & 200 & 100 \\
\hline
\end{tabular}

A categoria que obteve maior percentual foi a que considerou o mercado de trabalho difícil, ela apresenta as dificuldades que jovens esperam enfrentar no mercado de trabalho, tais como "está difícil pra quem não tem experiência", "difícil encontrar emprego" e "o salário não compensa o trabalho das pessoas". A segunda categoria mais citada descreveu o mercado de trabalho como competitivo/ que exige qualificação, afirmações como "empresas procurando pessoas qualificadas e pessoas não qualificadas procurando emprego" e "pouco emprego para muita gente" ilustram o tipo de resposta que os jovens ofereceram a essa categoria. Já a categoria que considera a situação do mercado como boa pode ser ilustrada pelas seguintes respostas: "está mais fácil para conseguir emprego" e "estão abrindo muitas oportunidades". Finalmen- te, a categoria desvalorização do profissional é composta por afirmações como: "trabalho não falta, mas ter um dinheiro bom está difícil".

Finalmente, os estudantes foram questionados sobre a relação que estabelecem entre seu futuro profissional e as coisas que almejam para sua vida. A Tabela 4 apresenta as respostas dos participantes a essa questão. A resposta mais frequente foi estudos/esforços pessoais (22\%), seguida de trabalho como fonte de satisfação (19\%). Os jovens também associaram seu futuro profissional com independência financeira $(9,5 \%)$, com a conciliação entre responsabilidades pessoais e profissionais $(9,5 \%)$, com o trabalho e a constituição da família $(7,5 \%)$ e com o prazer em desempenhar a profissão $(7,0 \%)$. Quarenta e dois participantes não responderam a essa pergunta.

\section{Tabela 4}

\section{Relação entre Futuro Profissional e o que os Estudantes Querem para Sua Vida}

\begin{tabular}{lcc}
\hline $\begin{array}{l}\text { Que relação você percebe entre seu futuro profissional e as coisas que } \\
\text { você quer para você na vida? }\end{array}$ & Frequência & Percentual \\
\hline Estudos/esforços pessoais & 44 & 22,0 \\
Trabalho como fonte de satisfação & 38 & 19,0 \\
Independência/ ganhos finaceiros & 19 & 9,5 \\
Conciliar lado pessoal com profissional & 19 & 9,5 \\
Trabalhar e formar a própria família & 15 & 7,5 \\
Gostar da profissão & 14 & 7,0 \\
Não pensa na relação nem no futuro & 5 & 2,5 \\
Relação pessimista & 4 & 2,0 \\
Não responderam a questão & 42 & 21,0 \\
\hline Total & 200 & 100 \\
\hline
\end{tabular}


Exemplos de afirmações da categoria estudo/esforços pessoais são "tudo que eu desejar obter para minha casa, minha vida vai depender do meu esforço e da minha vontade de crescer profissionalmente" e "estou fazendo de tudo para mim ter um futuro legal, ter uma profissão boa, ter uma vida boa e poder construir minha família". Já a categoria trabalho como fonte de satisfação agrupou respostas relacionadas ao prazer que o trabalho pode proporcionar, tais como "a felicidade da vida está muitas vezes na escolha profissional" e "quando você trabalha em uma profissão que gosta, você é feliz, não importa o valor do salário, importa o que você acha de sua profissão". Por sua vez, a categoria independência/ ganhos finaceiros foi composta por respostas como: "eu quero ter uma vida estável, me aposentar com um bom salário" e "eu quero uma vida sem problemas financeiros e estável". A categoria conciliar lado pessoal com profissional é representada por afirmações do tipo: "que irão andar juntos, lado pessoal com o profissional. É conciliar os dois lados" e "que eu vá bem tanto na vida particular quanto na profissional". Ainda a categoria trabalhar e formar a própria família pode ser exemplificada pelas afirmações: "ter uma profissão, me formar para fonte de sustento, pois mais tarde quero ter minha casa, meus filhos, mas ter como sustentar e "para tudo precisamos de dinheiro, por isso é importante estudar, para ter um emprego digno, e poder dar um futuro melhor para nossos filhos". A categoria gostar da profissão envolveu afirmações como: "onde eu trabalhe em algo que eu goste e me sinta bem" e "quero fazer alguma coisa que eu goste que só me deixar satisfeita com a profissão que estou seguindo". Finalmente, a categoria relação pessimista pode ser ilustrada através da resposta: "no trabalho atual não tenho como alcançar meus objetivos".

\section{Discussão}

A adolescência frequentemente é representada no senso comum como uma fase despreocupada, irresponsável, na qual o jovem busca vivenciar o presente e não se preocupar com o futuro. Entretanto, grande parte dos adolescentes descreve as angústias que sente, as dificuldades que vivência e as preocupações com o futuro ao falar de si (Paredes \& Pecora, 2004). A maioria dos alunos que respondeu ao questionário desta pesquisa afirmou pensar sobre o seu futuro profissional. Os jovens tenderam a associar o futuro profissional com esforço pessoal para conquistar sucesso profissional e boas condições financeiras, além de desejarem exercer uma profissão que lhes traga satisfação pessoal. Assim, o futuro é colocado como uma interrogação para os jovens, que frequentemente buscam refletir sobre o que podem vir a ser em suas profissões (Oliveira, Pinto, \& Souza, 2003). Tal fato vai ao encontro do estudo sobre a visão da constituição da carreira realizado por Ribeiro (2011) com jovens em situação de vulnerabilidade. O autor afirma que o discurso dos jovens por ele entrevistados indica uma falta de reflexão sobre o futuro, já que esses jovens possuem a necessidade iminente de cuidar do presente.

Os jovens que têm a oportunidade de chegar ao ensino médio, público-alvo desta pesquisa, são desafiados a definir um projeto de futuro. Contudo, a velocidade das transformações sociais, as incertezas econômicas globais e os avanços tecnológicos fazem com que os projetos para o futuro profissional sejam cada vez mais instáveis (Barreto \& Aiello-Vaisberg, 2007). Diante desse desafio, a maioria dos sujeitos deste estudo relacionou o futuro profissional com o esforço pessoal. Isso pode estar relacionado às expectativas que os jovens de classe socioeconômica desfavorecida têm em relação às diferenças entre o contexto escolar e os futuros ambientes de trabalho que terão de enfrentar, visualizando que será necessário grande empenho para chegar onde pretendem (Oliveira et al., 2003). Associado a essa realidade está o contexto laboral cada vez mais complexo, permeado por transformações e instabilidade nas profissões, que faz com que os indivíduos busquem constante qualificação de habilidades pessoais e técnicas (Jenschke, 2003; Lemos et al., 2009; Nunes \& Noronha, 2009 ). Nesse sentido, algumas dificuldades vivenciadas por essa população específica são apontadas, como o acesso precário a recursos educacionais e culturais, que deveriam 
complementar a educação escolar recebida (Sobrosa et al., 2012). Apesar disso, a maior parte dos participantes se mostrou otimista em relação ao futuro. Esses dados vão ao encontro dos resultados da pesquisa de Oliveira et al. (2003), na qual as autoras afirmam que a maioria dos jovens demonstra confiança no futuro e motivação para o alcance de metas. Entretanto, parece que a motivação dos adolescentes pode variar conforme o ano em que estão estudando no ensino médio, de forma que os alunos de primeiro ano demonstram mais dúvidas associadas aos planos profissionais, variável que não foi investigada neste estudo. Ademais, o fato de estudar em escola pública ou privada não está relacionado com maior ou menor nível de motivação dos estudantes, embora o pessimismo esteja mais frequentemente descrito em alunos de escolas públicas (Balbinotti, Tétreau, \& Gingras, 2009).

Em contrapartida, alguns jovens revelaram sentir dificuldades de tomar decisões ao pensar sobre o futuro profissional, respostas encontradas nesse estudo como: "penso em fazer a escolha certa para não me arrepender", "se vai ser fácil conseguir um emprego e onde que vai ser" e "eu penso: será que vou exercer bem minha profissão?" ilustram essa afirmação. Frequentemente, o futuro vem acompanhado pelo medo do fracasso ou das conseqüências de escolhas mal sucedidas (Oliveira et al., 2003). Contudo, os resultados encontrados nesta pesquisa contrariam o que normalmente é encontrado na literatura, já que apenas $4,5 \%$ dos sujeitos relacionaram seu futuro profissional com dúvidas em relação à autoeficácia. De qualquer forma, intervenções que visem envolver os alunos em atividades de exploração de si e do ambiente de forma ativa podem auxiliar esses adolescentes a organizar as informações obtidas e estabelecer planos futuros, diminuindo as dificuldades na tomada de decisão (Königstedt \& Taveira, 2010).

Os jovens participantes também afirmaram pensar o futuro em termos de sucesso profissional e pessoal e boas condições financeiras, o que foi entendido por Valore e Viaro (2007) como uma tentativa por parte dos jovens de "unir o útil ao agradável". Isso pode ser ilustrado nesse estudo pelas afirmações dos adolescentes: "poder ser uma profissional bem vista, e com uma remuneração razoável", "penso em ser uma profissional competente onde atuo" e "quero poder com meu futuro profissional conseguir tudo o que eu desejo economicamente". É provável que, por essa razão, a palavra futuro esteja diretamente associada ao trabalho-estudo, conforme é apontado em uma pesquisa sobre as representações sociais do trabalho em jovens do ensino médio de escolas públicas (Oliveira, Fischer, Teixeira, \& Sá, 2005). O trabalho continua, assim, desempenhando um papel central na vida dos jovens apesar da precarização das condições laborais (Ribeiro, 2011).

A concomitância das duas atividades, isto é, trabalhar e estudar, permite aos estudantes ascender em uma carreira profissional, além de representar a possibilidade de melhor qualidade de vida e superação da atual condição de classe (Oliveira et al., 2005; Ribeiro, 2011), a exemplo das respostas a seguir: "penso que para ter um bom futuro preciso estar qualificada" e "penso que se eu estudar, me esforçar eu tenho chances de me dar muito bem". Essas informações são similares às encontradas em um estudo realizado com adolescentes provenientes de nível socioeconômico desfavorecido. Esse trabalho encontrou que estes percebem o trabalho como algo benéfico, que, através dele, irão obter ganhos financeiros, o que lhes permite obter certa autonomia em relação aos pais. Além disso, estes jovens estão cientes da importância de obter uma boa formação escolar, bem como a necessidade de qualificação (Dutra-Thomé, Queiroz, \& Koller, 2010). Desta forma, acredita-se que a inserção destes no mercado de trabalho, aconteceria com maior facilidade.

Em outro estudo, realizado por Lachtim e Soares (2011) com jovens de uma cidade do interior do estado de São Paulo, o qual investigou os valores atribuídos por estes ao trabalho e suas expectativas de futuro, foi encontrado que os participantes relacionaram a necessidade de frequentar o ensino regular a uma boa colocação no mercado de trabalho. Além disso, o trabalho foi apontado por esses jovens como uma atividade essencial, de valor para suas vidas, pois, além de auxiliar na renda familiar, ele também pro- 
porciona a realização de um curso superior ou contribui para a quitação das despesas do ensino médio (Lachtim \& Soares, 2011). Assim, as atividades de trabalho e estudo se complementam na medida em que os jovens percebem que essa dinâmica contribui na conquista de suas expectativas futuras.

Entretanto, percebe-se que no Brasil as políticas públicas oferecidas para os jovens oriundos de níveis socioeconômicos desfavorecidos ainda são insuficientes, fazendo com que a dupla jornada trabalho/estudos não seja uma opção para esses jovens, mas sim a única a ser buscada. Isto ocorre devido à falta de políticas que priorizem um ensino de qualidade, visando uma trajetória educacional qualificada e consistente. Desta maneira, as condições de entrada no mundo do trabalho poderiam estar mais aproximadas, se comparadas às oportunidades de jovens de classes socioeconômicas favorecidas (Borges \& Coutinho, 2010).

De fato, diversas pesquisas realizadas com jovens demonstram que o trabalho é percebido como uma atividade primordial para a realização em diversas áreas da vida do indivíduo, este além de proporcionar renda própria também permite complementar a renda familiar (Borges \& Coutinho, 2010; Jesús \& Ordaz, 2006; Ribeiro, 2011). Desta forma, o trabalho, a formação acadêmica e a aquisição de bens materiais, juntamente com a formação de uma família, são os elementos mais comuns nos projetos de vida dos jovens (Rizzo \& Chamon, 2010; Santos, 2002). De certa forma, tais componentes também foram os que com maior constância apareceram nas respostas concedidas pelos sujeitos desta pesquisa, já que $16,5 \%$ deles pensa em seu futuro em termos de sucesso profissional e pessoal, $8,5 \%$ em boas condições financeiras e 7\% em gostar da profissão.

Entende-se, então, que a escolarização é reconhecida pelos jovens como pressuposto para a empregabilidade e como o diferencial na competitividade (Ribeiro, 2011; Valore \& Viaro, 2007). Afinal, o sucesso profissional aparece, normalmente, associado à formação em nível superior, já que os jovens percebem as dificuldades de colocação no mercado de trabalho (Oliveira, Sá, Fischer, Martins, \& Teixeira, 2001; Paredes $\&$ Pecora, 2004). Nesta pesquisa, grande parte dos sujeitos também enxergou a situação atual do mercado de trabalho de forma negativa, sendo que a maioria deles julgou-a como sendo difícil ("dificil, muita concorrência, não basta ser bom é preciso ser ótimo"), com o mercado competitivo, exigindo qualificação ("bastante disputado, não basta ser somente qualificado é preciso também ser ousado, criativo") e desvalorizando os profissionais ("as pessoas passam uma vida estudando e não recebem de acordo com o que mereciam").

O mercado de trabalho é uma das maiores preocupações apontadas no momento de escolher uma profissão, sendo, muitas vezes, decisivo nesse processo, incidindo diretamente no que os adolescentes imaginam para o seu futuro profissional. Normalmente, as visões dos jovens sobre o mercado de trabalho é determinada pela subjetividade e pelas influências do meio social em que o mesmo está inserido (Soares, Sestren, \& Ehlke, 2002). Ademais, a percepção sobre o mercado de trabalho pode não ser realista para jovens do ensino médio, uma vez que os mesmos podem estar mais preocupados com a definição de uma preferência profissional do que com a exploração do mercado laboral em si (Balbinotti et al., 2009), já que a indecisão vocacional pode ser mais frequente em estudantes de escolas públicas e de nível socioeconomico inferior (Locatelli, Bzuneck, \& Guimarães, 2007). Acredita-se que a visão pessimista da maioria dos sujeitos de pesquisa sobre o mercado de trabalho deveu-se às dificuldades percebidas pelos mesmos que seus pais e/ou parentes próximos possuem para se inserir no universo laboral. De fato, a ideia de desemprego seguidamente está associada a pessoas de classe social menos favorecida economicamente (Soares et al., 2002), assim como os jovens deste estudo.

Somado a isso, a atual conjuntura do mundo do trabalho é bastante complexa. É comum os jovens escolherem atuar em áreas que apresentem mais oportunidades de se inserir no mercado. Porém, esta é uma realidade que sofre mu- 
danças constantes, visto que uma área que hoje procura por profissionais daqui a um ano já pode estar saturada, enquanto outra saturada, daqui a alguns anos estará à procura de pessoas qualificadas para o trabalho (Soares et al., 2002). Nesse sentido, pode-se supor que a visão de alguns jovens em relação à desvalorização dos profissionais ou até mesmo em não saber o que pensar sobre o mercado de trabalho esteja associada à inconstância do mercado de trabalho.

No entanto, uma parcela considerável da amostra deste estudo acreditou que as atuais condições do mercado de trabalho são boas; respostas como "o mercado de trabalho está se expandindo bastante" e "eu acho que quem quer trabalhar consegue, basta se empenhar" ilustram essa afirmação. É possível que isso aconteça, pois a mídia com frequência apresenta modelos idealizados de ocupações, mostrando somente os benefícios das profissões e geralmente omitindo as dificuldades e adversidades que permeiam o seu exercício. Por outro lado, os jovens que enxergam o mercado de trabalho como bom podem estar pensando em seguir profissões atualmente valorizadas (Soares et al., 2002).

Por fim, destaca-se que grande parte dos jovens consegue traçar uma relação entre o futuro profissional e as coisas que almeja para sua vida, possibilitando aos sujeitos estabelecer sua futura trajetória produtiva com o mundo (Borges \& Coutinho, 2010). De maneira geral, a relação encontra-se no estudo, no trabalho e na família: "me formar, trabalhar e ter uma família" e "quero ter minha profissão ser independente, construir uma família, casar e talvez com o tempo mudar de cidade". Pesquisas realizadas apontam que o estudo e o trabalho são fortes aliados na construção de projetos de vida de jovens carentes (Dutra-Thomé et al., 2010; Nascimento, 2002). Somado a isso, a pertença ou constituição de uma família também é considerado importante para o futuro pelos jovens (Valore \& Viaro, 2007). Existe ainda uma afinidade entre o futuro profissional e a vontade de ser financeiramente independente, visto que os jovens anseiam por reconhecimento como sujeitos de direitos, bem como por oportunidades de emancipação e au- tonomia, através do trabalho e do desenvolvimento profissional (Raitz \& Petters, 2008; Torres, Paula, Ferreira, \& Pinheiro 2010). Assim, a inserção no mercado de trabalho e a formação educacional são vistos como elementos fundamentais para a passagem ao mundo adulto em grande parte da população jovem no Brasil, em especial para os indivíduos que necessitam exercer uma atividade laboral e colaborar no sustento da família (Mattos \& Chaves, 2010).

\section{Considerações Finais}

Este estudo buscou investigar as expectativas em relação ao futuro profissional de jovens estudantes do ensino médio oriundos de classes socioeconômicas desfavorecidas. Verificou-se que os estudantes, de maneira geral, são otimistas em relação ao futuro profissional e esperam conquistar sucesso pessoal e profissional. No entanto, apontam a necessidade de se esforçar para atingir seus objetivos e desfrutar da satisfação que o trabalho escolhido pode proporcionar, uma vez que percebem os aspectos negativos associados à instabilidade do mercado de trabalho.

Esta pesquisa possui limitações que devem ser consideradas na interpretação dos resultados apresentados. Deve-se ter cuidado ao generalizar esses dados, pois os participantes do estudo eram alunos somente de duas escolas públicas do interior do Rio Grande do Sul. É possível que jovens de instituições particulares da mesma região possuam percepções diferentes sobre seu futuro profissional. Adolescentes de outras regiões do país também podem estabelecer relações diferentes entre as expectativas quanto ao futuro profissional e mercado de trabalho. Diante disso, sugere-se que mais pesquisas sejam realizadas abrangendo estudantes de escolas públicas e privadas de diferentes regiões do Brasil ou, até mesmo, comparações entre países.

Questiona-se, ainda, se a visão pessismista ou otimista sobre a situação atual do mercado de trabalho e sobre as expectativas quanto ao seu futuro profissional apresentada pelos participantes pode ser mediada pelos comportamentos exploratórios que apresentam e pelos níveis de 
autoeficácia que possuem. Dessa forma, sugere-se que mais estudos sejam realizados abordando a possível relação entre essas variáveis.

\section{Referências}

Almeida, L. S., Guisante, M. A., Soares, A. P., \& Saavedra, L. (2006). Acesso e sucesso no ensino superior em Portugal: Questões de género, origem sócio-cultural e percurso acadêmico dos alunos. Psicologia: Reflexão e Crítica, 19(3), 507-514.

Balbinotti, M. A. A., Tétreau, B., \& Gingras, M. (2009). Motivação referente à carreira de alunos de 14 a 18 anos: Um estudo exploratório. Psico, 40(4), 478-490.

Bardagi, M. P., Lassance, M. C. P., \& Paradiso, A. C. (2003). Trajetória acadêmica e satisfação com a escolha profissional de universitários em meio de curso. Revista Brasileira de Orientação Profissional, 4(1-2), 153-166.

Bardin, L. (2009). Análise de conteúdo. Lisboa, Portugal: Edições 70.

Barreto, M. A., \& Aiello-Vaisberg, T. (2007). Escolha profissional e dramática do viver adolescente. Psicologia \& Sociedade, 19(1), 107-114.

Borges, R. C. P., \& Coutinho, M. C. (2010). Trajetórias juvenis: Significando projetos de vida a partir do primeiro emprego. Revista Brasileira de Orientação Profissional, 11(2), 189-200.

Brito, M. M. L. (2006). Juventude, pobreza e trabalho: Desafios para o mundo contemporâneo (Dissertação de mestrado, Universidade Estadual do Ceará, Fortaleza, CE, Brasil).

Burnier, S. (2006). Os significados do trabalho segundo técnicos do nível médio. Revista Educação \& Sociedade, 27(94), 131-157.

Dutra-Thomé, L., Queiroz, A. T., \& Koller, S. H. (2010). Inserção laboral juvenil: Contexto e opinião sobre definições de trabalho. Paidéia (Ribeirão Preto), 20(46), 175-185.

Gonçalves, H. S., Borsoi, T. S., Santiago, M. A., Lino, M. V., Lima, I. N., \& Frederico, R. G. (2008). Problemas da juventude e seus enfrentamentos: Um estudo de representações sociais. Revista de Psicologia Social, 20(2), 217-225.

Gottfredson, L. S. (1981). Circumscription and compromise: A developmental theory of occupational aspirations. Journal of Counseling Psychology Monograph, 28, 545-579.
Jenschke, B. (2003). A cooperação internacional: Desafios e necessidades da orientação e do aconselhamento em face das mudanças mundiais no trabalho e na sociedade. Revista Brasileira de Orientação Profissional, 4(1-2), 35-55.

Jesús, M., \& Ordaz, M. G. (2006). El significado del trabajo: estúdio comparativo entre jóvenes empleados e desempleados. Segunda Época, 25(2), 64-77.

Königstedt, M., \& Taveira, M. C. (2010). Exploração vocacional em adolescentes: Avaliação de uma intervenção em classe. Paidéia (Ribeirão Preto), 20(47), 303-312.

Lachtim, S. A. F., \& Soares, C. B. (2011). Valores atribuídos ao trabalho e expectativa de futuro: Como os jovens se posicionam? Trabalho, Educação e Saúde, 9(2), 277-293.

Lemos, A. H. C., Dubeux, V. J. C., \& Pinto, M. C. S. (2009). Educação, empregabilidade e mobilidade social: Convergências e divergências. Cadernos EBAPE.BR, 7(2), 368-384.

Locatelli, A. C. D., Bzuneck, J. A., \& Guimarães, S. E. R. (2007). A motivação de adolescentes em relação com a perspectiva de tempo futuro. Psicologia: Reflexão e Crítica, 20(2), 268-276.

Mattos, E. de, \& Chaves, A. M. (2010). Trabalho e escola: É possível conciliar? As perspectivas de jovens aprendizes baianos. Psicologia: Ciência e Profissão, 30(3), 540-555.

Minayo, M. C. S. (2000). O desafio do conhecimento: Pesquisa qualitativa em saúde. São Paulo, SP: Hucitec.

Melo, S. L. de, \& Borges, L. de O. (2007). A transição da universidade ao mercado de trabalho na ótica do jovem. Psicologia: Ciência e Profissão, 27(3).

Ministério da Saúde. (1997). Diretrizes e normas para pesquisa envolvendo seres humanos. Resolução CNS 196/96. Brasília, DF: Autor. Recuperado em 15 de dezembro de 2012, de http:// conselho.saude.gov.br/web_comissoes/conep/ aquivos/resolucoes/resolucoes.htm

Nascimento, I. P. (2002). As representações sociais do projeto de vida dos adolescentes: Um estudo psicossocial (Tese de doutorado, Pontifícia Universidade Católica de São Paulo, SP, Brasil).

Nunes, M. F. O., \& Noronha, A. P. P. (2009). Autoeficácia para atividades ocupacionais e interesses profissionais em estudantes do ensino médio. Psicologia: Ciência e Profissão, 29(1), 102-115. 
Oliveira, D. C., Fischer, F. M., Teixeira, M. C. T. V., \& Sá, C. P. (2005). A positividade e a negatividade do trabalho nas representações sociais de adolescentes. Psicologia: Reflexão e Crítica, $18(1), 125-133$.

Oliveira, D. C., Sá, C. P., Fischer, F. M., Martins, I. S., \& Teixeira, L. R. (2001). Futuro e liberdade: O trabalho e a instituição escolar nas representações sociais de adolescentes. Estudos de Psicologia (Natal), 6(2), 245-258.

Oliveira, M. C. S. L., Pinto, R. G., \& Souza, A. S. (2003). Perspectivas de futuro entre adolescentes: Universidade, trabalho e relacionamentos na transição para a vida adulta. Temas em Psicologia, 11(1), 16-27.

Paredes, E. C., \& Pecora, A. R. (2004). Questionando o futuro: As representações sociais de jovens estudantes [Edição especial]. Psicologia: Teoria e Prática, 49-65.

Raitz, T. R., \& Petters, L. C. F. (2008). Novos desafios dos jovens na atualidade: Trabalho, educação e família. Psicologia \& Sociedade, 20(3), 408-416.

Ribeiro, M. A. (2011). Juventude e trabalho: Construindo a carreira em situação de vulnerabilidade. Arquivos Brasileiros de Psicologia, 63, 1-104.

Ribeiro, R., \& Neder, H. D. (2009). Juventude(s): Desocupação, pobreza e escolaridade. Revista Nova Economia, 19(3), 475-506.

Rizzo, C. B. S., \& Chamon, E. M. Q. O. (2010). O sentido do trabalho para o adolescente trabalhador. Trabalho, Educação e Saúde, 8(3), $407-$ 417.
Rocha, S. (2008). A inserção dos jovens no mercado de trabalho. Caderno CRH, 21(54), 533-550.

Santos, M. I. (2002). Projetos de vida e perspectivas futuras: Um estudo sobre as representações sociais do tempo futuro presentes nos projetos de vida dos jovens (Dissertação de mestrado, Pontifícia Universidade Católica de São Paulo, SP, Brasil).

Soares, D. H. P., Sestren, G., \& Ehlke, S. B. (2002). A influência da percepção dos jovens sobre o mercado de trabalho na escolha profissional. Contrapontos, 2(5), 237-250.

Sobrosa, G. M. R., Camerin, C., Santos, A. S. dos, \& Dias, A. C. G. (2012). Considerações acerca da inserção profissional de jovens do ensino médio. Mudanças - Psicologia da Saúde, 20(1-2), 4149.

Torres, C. A., Paula, P. H. A., Ferreira, A. G. N., \& Pinheiro, P. N. C. (2010). Adolescência e trabalho: Significados, dificuldades e repercussões na saúde. Interface - Comunicação, Saúde, Educação, 14(35), 839-850.

Valore, L. A., \& Viaro, R. V. (2007). Profissão e sociedade no projeto de vida de adolescentes em orientação profissional. Revista Brasileira de Orientação Profissional, 8(2), 57-70.

Recebido: 10/06/2013

$1^{a}$ revisão: $21 / 08 / 2013$

$2^{a}$ revisão: $11 / 10 / 2013$

Aceite final: 07/11/2013 